\title{
Prospective Analysis of Association Between Use of Statins and Melanoma Risk in the Women's Health Initiative
}

\author{
Deepa Jagtap, MD ${ }^{1}$, Carol A. Rosenberg, MD², Lisa W. Martin, MD³, Mary Pettinger, MS ${ }^{4}$, \\ Janardan Khandekar, $\mathbf{M D}^{2}$, Dorothy Lane, MD, MPH $^{5}$, Ira Ockene, $\mathbf{M D}^{6}$, and Michael S. \\ Simon, MD, MPH ${ }^{1,7}$ \\ ${ }^{1}$ Department of Oncology, Karmanos Cancer Institute, Wayne State University, Detroit, Michigan \\ ${ }^{2}$ NorthShore University Health System, Evanston, Illinois \\ ${ }^{3}$ Division of Cardiology, George Washington School of Medicine, Washington DC \\ ${ }^{4}$ Public Health Sciences Division, Fred Hutchinson Cancer Research Center, Seattle, Washington \\ ${ }^{5}$ Department of Preventive Medicine, Stony Brook University School of Medicine, Stony Brook, \\ New York \\ ${ }^{6}$ University of Massachusetts Medical School, Worchester, Massachusetts \\ ${ }^{7}$ Population Studies and Prevention Program, Karmanos Cancer Institute, Wayne State \\ University, Detroit, Michigan
}

\section{Abstract}

BACKGROUND-Melanoma is the most lethal form of skin cancer, with an estimated 68,130 new cases and 8700 deaths in the United States in 2010. The increasing incidence and high death rate associated with metastatic disease support the need to focus on prevention. The authors used data from the Women's Health Initiative (WHI) to assess whether 3-hydroxy-3 methylglutaryl coenzyme A inhibitors (statins) are associated with a decreased risk of melanoma.

METHODS-The study population consisted of 119,726 postmenopausal white women, in which 1099 cases of malignant melanoma were identified over an average (istandard deviation) of 11.6 \pm 3.2 years. All diagnoses were confirmed by medical record review and pathology reports. Information on statin use was collected at baseline and during follow-up. Self-administered and interview-administered questionnaires were used to collect information on other risk factors. Cox proportional hazards regression was used to calculate hazard ratios (HRs) with $95 \%$ confidence intervals (CIs). Analyses investigated the association of any statin use, type, potency, lipophilic status, and duration of use with melanoma.

RESULTS-Statins were used by 8824 women (7.4\%) at baseline. The annualized rate of melanoma was $0.09 \%$ among statin users and $0.09 \%$ among nonusers The multivariable adjusted HR for statin users compared with nonusers was 1.14 (95\% CI, 0.91-1.43). There were no significant differences in risk based on statin type, potency, category, duration, or in timedependent models.

(C) 2012 American Cancer Society

Corresponding author: Michael S. Simon, MD, MPH, Barbara Ann Karmanos Cancer Institute, 4100 John R, 4221 HWCRC, Detroit, MI; Fax: (313) 576-8764; simonm@karmanos.org.

For a list of all the investigators who have contributed to WHI science, please visit: http://www.whiscience.org/publications/ WHI_investigators_longlist.pdf

CONFLICT OF INTEREST DISCLOSURES

The authors made no disclosures. 
CONCLUSIONS-There was no significant association between statin use and melanoma risk among postmenopausal women in the WHI.

\section{Keywords}

statins; melanoma; cohort study; epidemiology; cancer risk

\section{INTRODUCTION}

Melanoma is the most lethal form of skin cancer, ${ }^{1}$ with an estimated 68,130 new cases and 8700 deaths in the United States in $2010 .^{2}$ Melanoma incidence continues to rise, with an average annual increase of $3.1 \%$ per year, making it the most rapidly increasing cancer in the United States. ${ }^{3}$ Up to $65 \%$ of melanomas are related to exposure to ultraviolet (UV) radiation, especially UVB radiation,,${ }^{4,5}$ and an increased risk is associated with childhood/ adolescent sun exposure, sun exposure during later decades of life, ${ }^{6}$ sun beds, ${ }^{6-8}$ a tendency to burn, and the presence of multiple nevi. ${ }^{6,9}$ Other risk factors include family history, ${ }^{10}$ mutations in the $P 16$ gene, ${ }^{11}$ and smoking. ${ }^{12}$ The rapidly increasing incidence and the high death rate associated with advanced or metastatic disease ${ }^{13-15}$ support the need to focus on prevention.

Educational strategies devoted to protecting individuals against UV radiation have had a modest impact on melanoma incidence. Statins are known to have anticancer properties because of their antiangiogenic, proapoptotic, ${ }^{16-18}$ and growth-inhibiting effects. ${ }^{19}$ Preclinical studies in a mouse melanoma cell line have demonstrated inhibition of cell migration, invasion, adhesion, and metastasis. ${ }^{20}$ With an estimated 45 million Americans using statins for their cardioprotective effects, ${ }^{21}$ statins may provide an easy way in which to reduce the burden of melanoma.

Randomized controlled trials of statins in the setting of heart disease risk have yielded mixed results, and the majority of studies have identified no significant impact on melanoma risk, ${ }^{22,23}$ although 1 trial of lovastatin resulted in a significant risk reduction. ${ }^{24}$ In contrast, 3 nested case-control studies have revealed no significant effect of statins on melanoma risk. $^{25-27}$ To our knowledge, there are no previously published cohort studies evaluating the relation between statins and melanoma risk.

We used the Women's Health Initiative (WHI) cohort to assess the hypothesis that statins are associated with a lower risk of melanoma. The WHI is the largest cohort of postmenopausal women in the United States and provides a unique opportunity to study outcomes for relatively uncommon cancers like melanomas.

\section{MATERIALS AND METHODS}

\section{Study Population}

The WHI includes an observational study (OS) $(n=93,676)$ and a randomized controlled clinical trial $(\mathrm{CT})(\mathrm{n}=68,132)$, which were described previously in detail. Recruitment was conducted between October 1, 1993 and December 31, 1998 at 40 clinical centers in the United States. Women were eligible if they were ages 50 to 79 years, postmenopausal, planned to remain in the area where they lived at recruitment, and had an estimated survival of at least 3 years. ${ }^{29,30}$

The current analysis is based on 133,541 white women who were enrolled in the OS and CT, excluding those who had a previous cancer diagnosis except nonmelanomatous skin cancer (NMSC) and those with missing information on cancer history $(n=13,815)$. One woman was 
excluded with unknown information on statin use. The final sample included 67,032 women enrolled in the OS and 52,694 women enrolled in the CT $(n=119,726)$. Institutional review boards at the participating institutions approved all protocols and procedures, and informed consent forms were signed by all participants. Follow-up for this report is through September 30, 2010, for a mean \pm standard deviation follow-up of $11.6 \pm 3.2$ years.

\section{Statin Exposure}

Participants were asked to bring all current prescription medication containers to their first screening interview (baseline), and interviewers entered each medication name directly into the database assigning drug codes using Medispan software (Frist DataBank, Inc., San Bruno, Calif), including duration of use. Mediation use was updated using the same methodology at the years 1, 3, 6, and 9 in the CT and at year 3 in the OS.

Statins were defined as any 3-hydroxy-3 methylglutaryl coenzyme A (HMG-CoA) reductase inhibitors and were classified based on solubility in octanol (lipophilicity) or water (hydrophilicity). ${ }^{32,32}$ Lipophilic statins (lovastatin, simvastatin, fluvastatin, and cerivastatin) penetrate the plasma membrane, whereas hydrophilic statins (pravastatin, atorvastatin, and rosuvastatin) do not. ${ }^{33-35}$ Statins were classified according to their potency based on lipidlowering efficacy as low (fluvastatin and lovastatin), medium (pravastatin), and high (simavastatin, atorvastatin, cerivastatin, and rosuvastatin). ${ }^{34-36}$

\section{Melanoma Diagnosis}

Cancer diagnoses were updated annually in the OS or semiannually in the CT by mail and/or telephone questionnaires. Self-reports or next-of-kin reports of melanoma were verified by centrally trained physician adjudicators after review of medical records and pathology reports using the Surveillance, Epidemiology, and End Results (SEER) coding system. ${ }^{37}$ Only 1099 centrally adjudicated and SEER-coded cases of cutaneous melanoma were included. We excluded 27 cases $(2.40 \%)$ that were not centrally confirmed and 40 cases of uveal melanomas that were not SEER coded.

\section{Covariates}

Information on age, race and ethnicity, geographic region by latitude, education, current and past smoking status, current and past alcohol intake, total energy expenditure in metabolic equivalent hours per week, current health provider, and history of NMSC were ascertained by baseline questionnaires. Other medication use included nonsteroidal anti-inflammatory drugs (NSAIDS) and aspirin. Body mass index was calculated as weight in kilograms divided by height in meters squared $\left(\mathrm{kg} / \mathrm{m}^{2}\right)$.

Current and previous use of menopausal hormone therapy and oral contraceptives was ascertained by using a detailed questionnaire, including type, route of administration, the number of pills per day or week, and the duration of use for each hormone preparation. Hormone therapy users were defined as those who used estrogen (with or without progestin) after menopause for at least 3 months.

We included information on geographic region, education, income, and exercise as a proxy for solar UV exposure. Current health care provider was included as an additional proxy for quality of health care and medical surveillance. Tobacco use is linked to skin cancers of all types, ${ }^{12}$ and hormone therapy use may be linked to melanoma development, because melanocytes have hormone receptors. ${ }^{38}$ 


\section{Statistical Methods}

The characteristics of statin users at baseline were compared with those of nonusers by using chi-square tests. Annualized melanoma rates were calculated as the percentage of women with an event divided by total follow-up time in years by statin use categories at baseline. Subgroup analyses were performed by statin use duration ( $<1$ year vs 1 to $<3$ years and $\geq 3$ years as well as $<5$ years vs $\geq 5$ years), type, potency, and lipophilic status. Use of 2 or more statins was included in analyses that compared statin use with none and were excluded from analyses that examined details of statin use according to type, potency, or lipophilic status.

Cox proportional hazards analyses were used to assess associations between statin use and melanoma risk. Age-adjusted and multivariable-adjusted models were developed, and both were stratified by age decade, assignment to active hormone or placebo in the $2 \mathrm{WHI}$ hormone trials (estrogen plus progestin and estrogen alone), assignment to intervention or control in the dietary modification trial, enrollment in the OS, and extension study participation. To control for confounding, the multivariable model also was adjusted for linear age, education, smoking, alcohol use, physical activity, body mass index, report of a current health care provider, geographic region by latitude (based on the clinical center where the participant enrolled), current hormone therapy use, history of NMSC, and NSAID use. To evaluate the effects of change in statin use over time, models were rerun by entering statin use as a time-dependent exposure and using updated information on statins gathered at follow-up clinic visits. Comparisons of risk of melanoma by tumor characteristics between statin users and nonusers were based on Cox models and competing-risk, partial-likelihood methods.

Tests for the proportional hazards assumptions were conducted by using a Cox model that included statin use and the interaction of statin use with follow-up time and that tested for a zero coefficient on the interaction term. Results of these analyses indicated that the assumptions were not violated. All analyses were conducted using SAS software (version 9.2; SAS Institute, Inc., Cary, NC). All statistical tests were 2-sided with a significance level of $P=.05$.

\section{RESULTS}

There were 8824 statin users $(7.4 \%)$ in a cohort of 119,726 women at baseline. Table 1 lists baseline characteristics according to statin use. Although most of the absolute differences between statin users and nonusers were small, many were statistically significant because of the large number of women. Statin users were more likely than nonusers to be older (mean age \pm standard deviation, $65.8 \pm 6.4$ years and $63.2 \pm 7.2$ years, respectively), to have a higher body mass index $\left(28.7 \pm 5.4 \mathrm{~kg} / \mathrm{m}^{2}\right.$ and $27.6 \pm 5.8 \mathrm{~kg} / \mathrm{m}^{2}$, respectively), to have smoked, to have a current health care provider, to have 1 or more comorbid medical conditions, to have used aspirin, and to have a diagnosis of NMSC. Statin users were less likely to have higher education, high family income, drink alcohol, and use hormone therapy. No difference was noted by geographic region.

Table 2 provides the distribution of statin users at baseline other characteristics. Simvastatin was the most common followed closely by lovastatin. Of 8824 statin users, 3390 women (38.4\%) used a low-potency statin, 1895 (21.5\%) used a medium-potency statin, and 3318 (37.6\%) used a high-potency statin (Table 2). In total, 6033 women (68.4\%) who used statins reported at least 1 lipophlic statin. Among statin users, 1479 participants (16.8\%) took statins for $\geq 5$ years, 2940 (33.3\%) took statins for $\geq 3$ years, 2966 (33.6\%) took statins for 1 to 3 years, and 2918 (33.1\%) took statins for $<1$ year. 
Table 3 lists the incidence of melanoma and HRs according to statin use among WHI participants. There were 89 women with melanoma among statin users for a yearly incidence of $0.09 \%$ ( 9 cases per 10,000 person-years of follow-up) compared with $0.09 \%$ for nonusers. There were no significant differences in the risk of melanoma in the age-adjusted and WHI trial-adjusted model (HR, 1.07; 95\% CI, 0.86-1.33) or in the multivariableadjusted model (HR, 1.14; 95\% CI, 0.91-1.43; P=.25) There were no significant differences in risk for type of statin, potency, category, or duration. When statin use reported at years 1 , 3,6 , and 9 was incorporated into a time-dependent model, there was no significant effect of statins on the risk of melanoma (HR, 0.98; 95\% CI, 0.820-1.16; data not shown). Regional, distant, and unknown tumor stages were twice as common among nonstatin users $(6.2 \%$ vs $3.4 \%$ ) than among users; however, there was no overall significant effect according to tumor stage (Table 4). Most melanomas were local stage followed by in situ and regional or distant stage.

\section{DISCUSSION}

We hypothesized that statins are associated with a lower risk of melanoma based on preclinical data suggesting that simvastatin decreased the ability of melanoma cells to adhere to laminin and collagen type IV, thereby decreasing proliferation, cell migration, invasion, and melanoma-induced angiogenesis, ${ }^{39}$ as well as findings from 1 randomized control trial. ${ }^{24}$ Our results, however, demonstrated no protective effect of statins when statins were considered as a class of drugs or for individual types of statins, potency, or duration of use. In addition, we observed no significant relation according to tumor stage; however, advanced tumors were slightly more common among nonstatin users compared with statin users ( $6.2 \%$ vs $3.4 \%)$, suggesting that statin users may have more opportunity for diagnosis at an earlier stage. It should be noted, however, that this observation was based on only 3 cases among statin users. It is also noteworthy that statin users in the WHI were more likely to have a current health care provider than nonusers, supporting the observation of an earlier stage at diagnosis among users. Thus, statin use may not be associated with a protective effect but, rather, may serve as a proxy indicator for factors that reflect greater medical surveillance. ${ }^{40}$

The results presented here represent the first report to our knowledge of the effect of statins on the incidence of melanoma from a cohort analysis and include a larger number of cases of melanoma and person-years of follow-up than were reported in either of the 2 previously published meta-analyses. ${ }^{22,23}$ Our results confirm those of others, including 9 randomized controlled trials ${ }^{41-49}$ and 3 nested case-control studies. ${ }^{25-27}$ The reported randomized controlled trials initially were designed to assess the relation between statins and cardiovascular outcomes, follow-up ranged from 24 weeks ${ }^{41,44}$ to 6.1 years, ${ }^{49}$ and the number of cases ranged from 0 to 58 . Results from some studies suggested trends toward a reduced risk, ${ }^{22,24,50-52}$ with pooled analyses of fluvastatin indicating a nonsignificant reduction in risk of melanoma ( 3 cases vs 7 cases; relative risk, $0.40 ; 95 \%$ CI, $0.10-1.55$ ). ${ }^{22}$ Others results have suggested a trend toward an increase in melanoma risk. ${ }^{53-56}$ Only Downs et al reported a significant reduction in melanoma incidence among individuals who were randomized to receive lovastatin, including 14 patients in the treatment group versus 27 patients in the placebo group (relative risk, $0.52 ; 95 \%$ CI, 0.27-0.99). ${ }^{24}$ Similarly, nested case-control studies have not demonstrated a significant effect of statins and melanoma risk. $^{25-27}$

It is possible that clinical and population-based studies of statins and melanoma do not demonstrate a preventive effect of statins because of inadequate dosing and drug concentrations at the cellular level. These results are in contrast to in vitro data, which suggest an anticarcinogenic effect in melanoma cell lines. ${ }^{19,39}$ A recent analysis indicated 
that the efficacy of statins in reducing colorectal cancer risk may be related to genetic variation in HMG-CoA reductase activity, ${ }^{57}$ which suggests that genetic heterogeneity may play a role in the lack of a protective effect of statins on cancer risk. Future studies that focus on individuals who have a greater risk of melanoma may provide more conclusive results.

Strengths of this study include the large cohort size as well as the large number of reported melanoma cases. In addition, we collected detailed information on a comprehensive range of melanoma risk factors, including blinded adjudication of malignant melanoma by pathology report review and description of melanoma histologic characteristics, and we had the ability to examine associations by statin category. Limitations include the observational design and that there may be residual confounding by unmeasured factors. For example, we did not have a direct measure of solar UV exposure, but we used other proxy measures, such as latitude of residence, physical activity, education, and income, to approximate sun exposure. Other limitations include the relatively low prevalence of statin use at baseline; inaccurate estimation of the overall duration of statin use, including the possibility that other statins may have been used after the last medication history was documented; the lack of information on statin dose; the low incidence of melanoma in our cohort; and the limited power to examine long-term effects.

In conclusion, although biologically plausible, there was no significant reduction in the risk of melanoma among users of statins among postmenopausal women in the WHI cohort. On current evidence, sun protection is the only way to prevent melanoma.

\section{Acknowledgments}

\section{FUNDING SOURCES}

The Women's Health Initiative program is funded by the National Heart, Lung, and Blood Institute, National Institutes of Health (NIH), US Department of Health and Human Services through contracts N01WH22110, 24152, 32100-2, 32105-6, 32108-9, 32111-13, 32115, 32118-32119, 32122, 42107-26, 42129-32, and 44221 and by Cancer Center Support grant NIH:NCI P30CA022453.

We acknowledge the dedicated efforts of investigators and staff at the Women's Health Initiative (WHI) clinical centers; the WHI Clinical Coordinating Center; and the National Heart, Lung, and Blood program office (listing available at http://www.whi.org). We also recognize the WHI participants for their extraordinary commitment to the WHI program.

\section{References}

1. Shoo BA, Kashani-Sabet M. Melanoma arising in African-, Asian-, Latino- and Native-American populations. Semin Cutan Med Surg. 2009; 28:96-102. [PubMed: 19608060]

2. SEER*Stat Database: Incidence-SEER 9 Registries Research Data, November 2010 submission (1973-2008) (Katrina/Rita Population Adjustment)—Linked to County Attributes; Total US, 1969_ 2009 Counties. Bethesda, MD: National Cancer Institute, DCCPS, Surveillance Research Program, Cancer Statistics Branch; 2011. Surveillance, Epidemiology and End Results (SEER) Program. (www.seer.cancer.gov)[released April 2011, based on the November 2012 submission].

3. Linos E, Swetter SM, Cockburn MG, Colditz GA, Clarke CA. Increasing burden of melanoma in the United States. J Invest Dermatol. 2009; 129:1666-1674. [PubMed: 19131946]

4. Bandarchi B, Ma L, Navab R, Seth A, Rasty G. From melanocyte to metastatic malignant melanoma [serial online]. Dermatol Res Pract. 2010; 2010:pii.

5. Chang NB, Feng R, Gao Z, Gao W. Skin cancer incidence is highly associated with ultraviolet-B radiation history. Int J Hyg Environ Health. 2010; 213:359-368. [PubMed: 20619731]

6. Veierod MB, Adami HO, Lund E, Armstrong BK, Weiderpass E. Sun and solarium exposure and melanoma risk: effects of age, pigmentary characteristics, and nevi. Cancer Epidemiol Biomarkers Prev. 2010; 19:111-120. [PubMed: 20056629] 
7. Cust AE, Armstrong BK, Goumas C, et al. Sunbed use during adolescence and early adulthood is associated with increased risk of early onset melanoma. Int J Cancer. 2011; 128:2425-2435. [PubMed: 20669232]

8. Lazovich D, Vogel RI, Berwick M, Weinstock MA, Anderson KE, Warshaw EM. Indoor tanning and risk of melanoma: a case-control study in a highly exposed population. Cancer Epidemiol Biomarkers Prev. 2010; 19:1557-1568. [PubMed: 20507845]

9. Godden D, Brennan PA, Milne J. Update on melanoma: the present position. Br J Oral Maxillofac Surg. 2010; 48:575-578. [PubMed: 20015580]

10. Manganoni AM, Zanotti F, Farisoglio C, Feroldi P, Facchetti F, Calzavara-Pinton P. Important risk factors in melanoma from the Dermato-Oncologic Unit of Brescia, Italy [serial online]. Dermatol Online J. 2010; 16:17. [PubMed: 20137759]

11. Santillan AA, Cherpelis BS, Glass LF, Sondak VK. Management of familial melanoma and nonmelanoma skin cancer syndromes. Surg Oncol Clin North Am. 2009; 18:73-98. viii.

12. Nagore E, Hueso L, Botella-Estrada R, et al. Smoking, sun exposure, number of nevi and previous neoplasias are risk factors for melanoma in older patients (60 years and over). J Eur Acad Dermatol Venereol. 2010; 24:50-57. [PubMed: 19563496]

13. Markovic SN, Geyer SM, Dawkins F, et al. A phase II study of bortezomib in the treatment of metastatic malignant melanoma. Cancer. 2005; 103:2584-2589. [PubMed: 15887220]

14. Croghan GA, Suman VJ, Maples WJ, et al. A study of paclitaxel, carboplatin, and bortezomib in the treatment of metastatic malignant melanoma: a phase 2 consortium study. Cancer. 2010; 116:3463-3468. [PubMed: 20564112]

15. Mouawad R, Sebert M, Michels J, Bloch J, Spano JP, Khayat D. Treatment for metastatic malignant melanoma: old drugs and new strategies. Crit Rev Oncol Hematol. 2010; 74:27-39. [PubMed: 19781957]

16. Saito A, Saito N, Mol W, et al. Simvastatin inhibits growth via apoptosis and the induction of cell cycle arrest in human melanoma cells. Melanoma Res. 2008; 18:85-94. [PubMed: 18337644]

17. Glynn SA, O’Sullivan D, Eustace AJ, Clynes M, O’Donovan N. The 3-hydroxy-3-methylglutarylcoenzyme A reductase inhibitors, simvastatin, lovastatin and mevastatin inhibit proliferation and invasion of melanoma cells [serial online]. BMC Cancer. 2008; 8:9. [PubMed: 18199328]

18. Minichsdorfer C, Hohenegger M. Autocrine amplification loop in statin-induced apoptosis of human melanoma cells. Br J Pharmacol. 2009; 157:1278-1290. [PubMed: 19563533]

19. Sora MK, Kruszewski AA, Stoklosa T, et al. Synergistic antiproliferative activity of tumor necrosis factor alpha (TNF-alpha) and lovastatin. Arch Immunol Ther Exp (Warsz). 1994; 42:269-274. [PubMed: 7487365]

20. Kidera Y, Tsubaki M, Yamazoe Y, et al. Reduction of lung metastasis, cell invasion, and adhesion in mouse melanoma by statin-induced blockade of the Rho/Rho-associated coiled-coil-containing protein kinase pathway [serial online]. J Exp Clin Cancer Res. 2010; 29:127. [PubMed: 20843370]

21. Spatz ES, Canavan ME, Desai MM. From here to JUPITER: identifying new patients for statin therapy using data from the 1999-2004 National Health and Nutrition Examination Survey. Circ Cardiovasc Qual Outcomes. 2009; 2:41-48. [PubMed: 20031811]

22. Freeman SR, Drake AL, Heilig LF, et al. Statins, fibrates, and melanoma risk: a systematic review and meta-analysis. J Natl Cancer Inst. 2006; 98:1538-1546. [PubMed: 17077356]

23. Bonovas S, Nikolopoulos G, Filioussi K, Peponi E, Bagos P, Sitaras NM. Can statin therapy reduce the risk of melanoma? A meta-analysis of randomized controlled trials. Eur J Epidemiol. 2010; 25:29-35. [PubMed: 19844794]

24. Downs JR, Clearfield M, Weis S, et al. Primary prevention of acute coronary events with lovastatin in men and women with average cholesterol levels: results of AFCAPS/TexCAPS. Air Force/ Texas Coronary Atherosclerosis Prevention Study. JAMA. 1998; 279:1615-1622. [PubMed: 9613910]

25. Blais L, Desgagne A, LeLorier J. 3-Hydroxy-3-methylglutaryl coenzyme A reductase inhibitors and the risk of cancer: a nested case-control study. Arch Intern Med. 2000; 160:2363-2368. [PubMed: 10927735]

26. Graaf MR, Beiderbeck AB, Egberts AC, Richel DJ, Guchelaar HJ. The risk of cancer in users of statins. J Clin Oncol. 2004; 22:2388-2394. [PubMed: 15197200] 
27. Kaye JA, Jick H. Statin use and cancer risk in the General Practice Research Database. Br J Cancer. 2004; 90:635-637. [PubMed: 14760377]

28. Design of the Women's Health Initiative clinical trial and observational study. The Women's Health Initiative Study Group. Control Clin Trials. 1998; 19:61-109. [PubMed: 9492970]

29. Langer RD, White E, Lewis CE, Kotchen JM, Hendrix SL, Trevisan M. The Women's Health Initiative Observational Study: baseline characteristics of participants and reliability of baseline measures. Ann Epidemiol. 2003; 13:S107-S121. [PubMed: 14575943]

30. Anderson GL, Manson J, Wallace R, et al. Implementation of the Women's Health Initiative study design. Ann Epidemiol. 2003; 13:S5-S17. [PubMed: 14575938]

31. Hamelin BA, Turgeon J. Hydrophilicity/lipophilicity: relevance for the pharmacology and clinical effects of HMG-CoA reductase inhibitors. Trends Pharmacol Sci. 1998; 19:26-37. [PubMed: 9509899]

32. Schachter M. Chemical, pharmacokinetic and pharmacodynamic properties of statins: an update. Fundam Clin Pharmacol. 2005; 19:117-125. [PubMed: 15660968]

33. Duncan RE, El-Sohemy A, Archer MC. Statins and the risk of cancer. JAMA. 2006; 295:27202722. [PubMed: 16788123]

34. Bischoff H, Heller AH. Preclinical and clinical pharmacology of cerivastatin. Am J Cardiol. 1998; $82: 18 \mathrm{~J}-25 \mathrm{~J}$.

35. Davidson MH. Rosuvastatin: a highly efficacious statin for the treatment of dyslipidaemia. Expert Opin Investig Drugs. 2002; 11:125-141.

36. Jones P, Kafonek S, Laurora I, Hunninghake D. Comparative dose efficacy study of atorvastatin versus simvastatin, pravastatin, lovastatin, and fluvastatin in patients with hypercholesterolemia (the CURVES study). Am J Cardiol. 1998; 81:582-587. [PubMed: 9514454]

37. Curb JD, McTiernan A, Heckbert SR, et al. Outcomes ascertainment and adjudication methods in the Women's Health Initiative. Ann Epidemiol. 2003; 13:S122-S128. [PubMed: 14575944]

38. Jee SH, Lee SY, Chiu HC, Chang CC, Chen TJ. Effects of estrogen and estrogen receptor in normal human melanocytes. Biochem Biophys Res Commun. 1994; 199:1407-1412. [PubMed: 8147884]

39. Pasco S, Brassart B, Ramont L, Maquart FX, Monboisse JC. Control of melanoma cell invasion by type IV collagen. Cancer Detect Prev. 2005; 29:260-266. [PubMed: 15936594]

40. Bonovas S, Sitaras NM. Statins and cancer risk: a confounded association. Gastroenterology. 2009; 137:740-741. [PubMed: 19563833]

41. Gentile S, Turco S, Guarino G, et al. Comparative efficacy study of atorvastatin vs simvastatin, pravastatin, lovastatin and placebo in type 2 diabetic patients with hypercholesterolaemia. Diabetes Obes Metab. 2000; 2:355-362. [PubMed: 11225965]

42. Athyros VG, Papageorgiou AA, Mercouris BR, et al. Treatment with atorvastatin to the National Cholesterol Educational Program goal versus "usual" care in secondary coronary heart disease prevention. The Greek Atorvastatin and Coronary-Heart-Disease Evaluation (GREACE) study. Curr Med Res Opin. 2002; 18:220-228. [PubMed: 12201623]

43. Arntz HR, Agrawal R, Wunderlich W, et al. Beneficial effects of pravastatin (icolestyramine/ niacin) initiated immediately after a coronary event (the randomized Lipid-Coronary Artery Disease [L-CAD] Study). Am J Cardiol. 2000; 86:1293-1298. [PubMed: 11113401]

44. Albert MA, Danielson E, Rifai N, Ridker PM. Effect of statin therapy on C-reactive protein levels: the Pravastatin Inflammation/CRP Evaluation (PRINCE): a randomized trial and cohort study. JAMA. 2001; 286:64-70. [PubMed: 11434828]

45. Boright AP, Connelly PW, Brunt JH, Morgan K, Hegele RA. Association and linkage of LDLR gene variation with variation in plasma low density lipoprotein cholesterol. J Hum Genet. 1998; 43:153-159. [PubMed: 9747026]

46. Serruys PW, de Feyter P, Macaya C, et al. Lescol Intervention Prevention (LIPS) Investigators. Fluvastatin for prevention of cardiac events following successful first percutaneous coronary intervention: a randomized controlled trial. JAMA. 2002; 287:3215-3222. [PubMed: 12076217]

47. Serruys PW, Foley DP, Jackson G, et al. A randomized placebo--controlled trial of fluvastatin for prevention of restenosis after successful coronary balloon angioplasty; final results of the 
Fluvastatin Angiographic Restenosis (FLARE) trial. Eur Heart J. 1999; 20:58-69. [PubMed: 10075142]

48. Herd JA, Ballantyne CM, Farmer JA, et al. Effects of fluvastatin on coronary atherosclerosis in patients with mild to moderate cholesterol elevations (Lipoprotein and Coronary Atherosclerosis Study [LCAS]). Am J Cardiol. 1997; 80:278-286. [PubMed: 9264419]

49. Riegger G, Abletshauser C, Ludwig M, et al. The effect of fluvastatin on cardiac events in patients with symptomatic coronary artery disease during 1 year of treatment. Atherosclerosis. 1999; 144:263-270. [PubMed: 10381299]

50. Stegmayr BG, Brannstrom M, Bucht S, et al. Low-dose atorvastatin in severe chronic kidney disease patients: a randomized, controlled endpoint study. Scand J Urol Nephrol. 2005; 39:489_ 497. [PubMed: 18161210]

51. Shepherd J, Cobbe SM, Ford I, et al. Prevention of coronary heart disease with pravastatin in men with hypercholesterolemia. West of Scotland Coronary Prevention Study Group. N Engl J Med. 1995; 333:1301-1307. [PubMed: 7566020]

52. Results of the low-dose $(20 \mathrm{mg})$ pravastatin GISSI Prevenzione trial in 4271 patients with recent myocardial infarction: do stopped trials contribute to overall knowledge? GISSI Prevenzione Investigators (Gruppo Italiano per lo Studio della Sopravvivenza nell'Infarto Miocardico). Ital Heart J. 2000; 1:810-820. [PubMed: 11302109]

53. Marschner IC, Colquhoun D, Simes RJ, et al. Long-term risk stratification for survivors of acute coronary syndromes. Results from the Long-Term Intervention with Pravastatin in Ischemic Disease (LIPID) Study LIPID Study Investigators. J Am Coll Cardiol. 2001; 38:56-63. [PubMed: 11451296]

54. Heart Protection Study Collaborative Group. The effects of cholesterol lowering with simvastatin on cause-specific mortality and on cancer incidence in 20,536 high-risk people: a randomised placebo-controlled trial [ISRCTN48489393] [serial online]. BMC Med. 2005; 3:6. [PubMed: 15771782]

55. Randomised trial of cholesterol lowering in 4444 patients with coronary heart disease: the Scandinavian Simvastatin Survival Study (4S). Lancet. 1994; 344:1383-1389. [PubMed: 7968073]

56. Sacks FM, Pfeffer MA, Moye LA, et al. The effect of pravastatin on coronary events after myocardial infarction in patients with average cholesterol levels. Cholesterol and Recurrent Events Trial investigators. N Engl J Med. 1996; 335:1001-1009. [PubMed: 8801446]

57. Lipkin SM, Chao EC, Moreno V, et al. Genetic variation in 3-hydroxy-3-methylglutaryl CoA reductase modifies the chemopreventive activity of statins for colorectal cancer. Cancer Prev Res (Phila). 2010; 3:597-603. [PubMed: 20403997] 


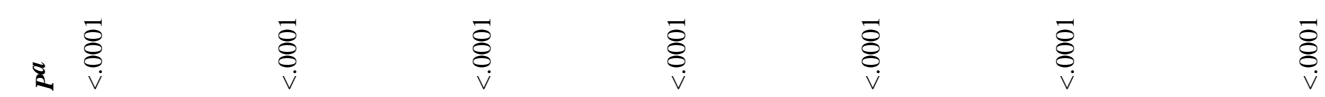
政

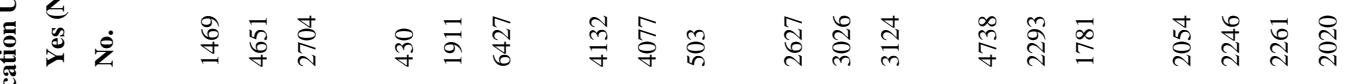

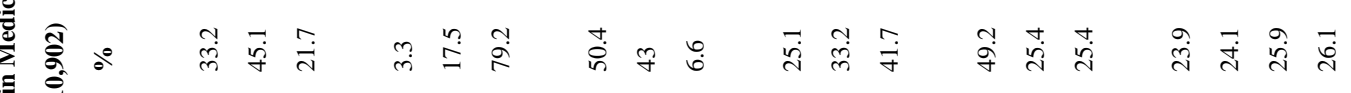

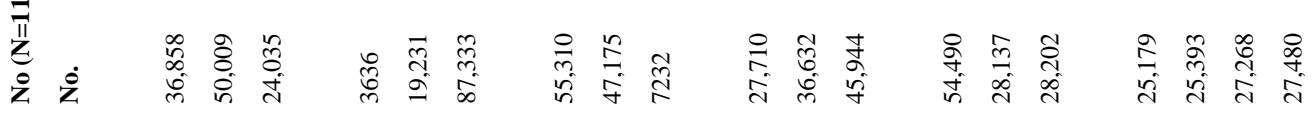

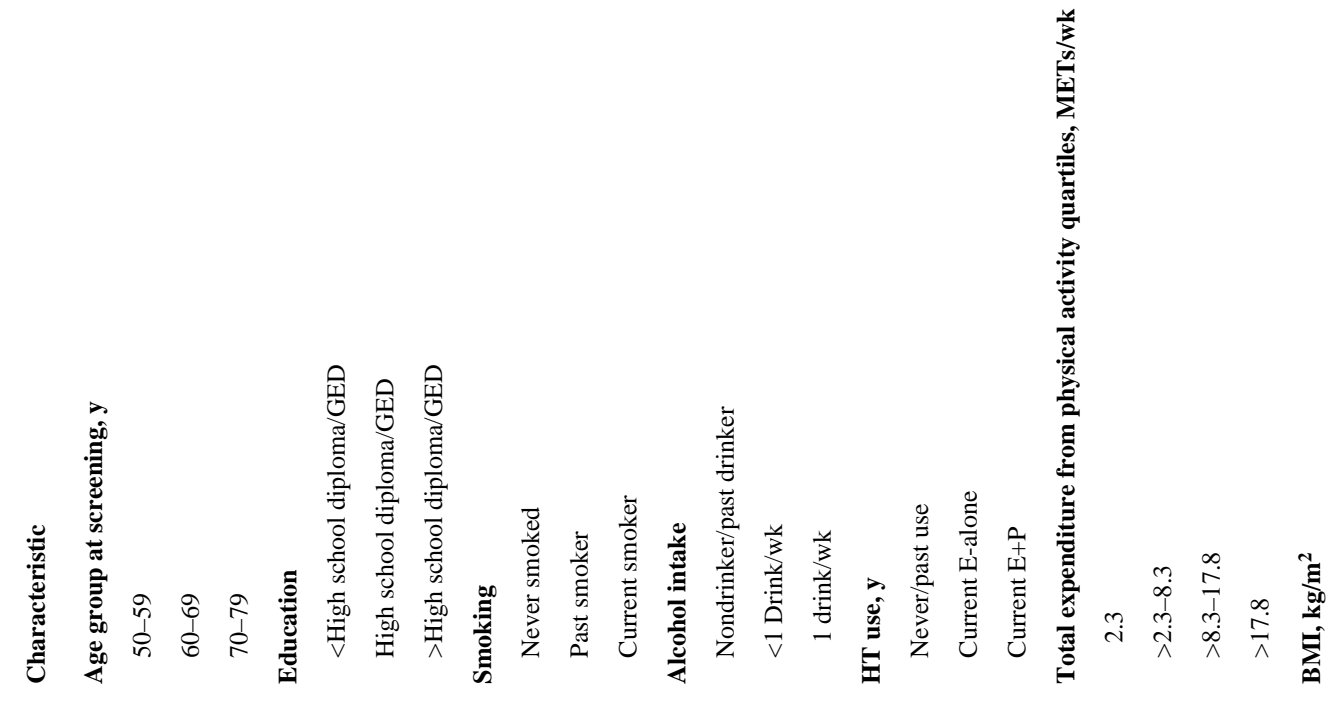


Table 2

Statin Use Details Among White Clinical Trials and Observational Study Participants (N=8824)

\begin{tabular}{|c|c|c|}
\hline Variable & No. of Patients & $\%$ \\
\hline \multicolumn{3}{|l|}{ Type of statin used } \\
\hline Atorvastatin calcium & 675 & 7.6 \\
\hline Fluvastatin sodium & 1036 & 11.7 \\
\hline Lovastatin & 2354 & 26.7 \\
\hline Pravastatin sodium & 1895 & 21.5 \\
\hline Simvastatin & 2643 & 30 \\
\hline$\geq 2$ Statins & 221 & 2.5 \\
\hline \multicolumn{3}{|l|}{ Statin potency ${ }^{a}$} \\
\hline Low (lovastatin, fluvastatin) & 3390 & 38.4 \\
\hline Medium (pravastatin) & 1895 & 21.5 \\
\hline High (simvastatin, atorvastatin) & 3318 & 37.6 \\
\hline \multicolumn{3}{|l|}{ Statin category $^{a}$} \\
\hline Lipophilic (fluvastatin, lovastatin, simvastatin) & 6033 & 68.4 \\
\hline Other (atorvastatin, pravastatin) & 2570 & 29.1 \\
\hline \multicolumn{3}{|l|}{ Statin use duration, $y$} \\
\hline$<1$ & 2918 & 33.1 \\
\hline 1 to $<3$ & 2966 & 33.6 \\
\hline$\geq 3$ & 2940 & 33.3 \\
\hline$<5$ & 7345 & 83.2 \\
\hline 25 & 1479 & 16.8 \\
\hline
\end{tabular}

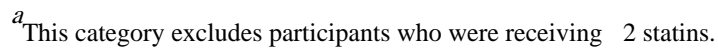




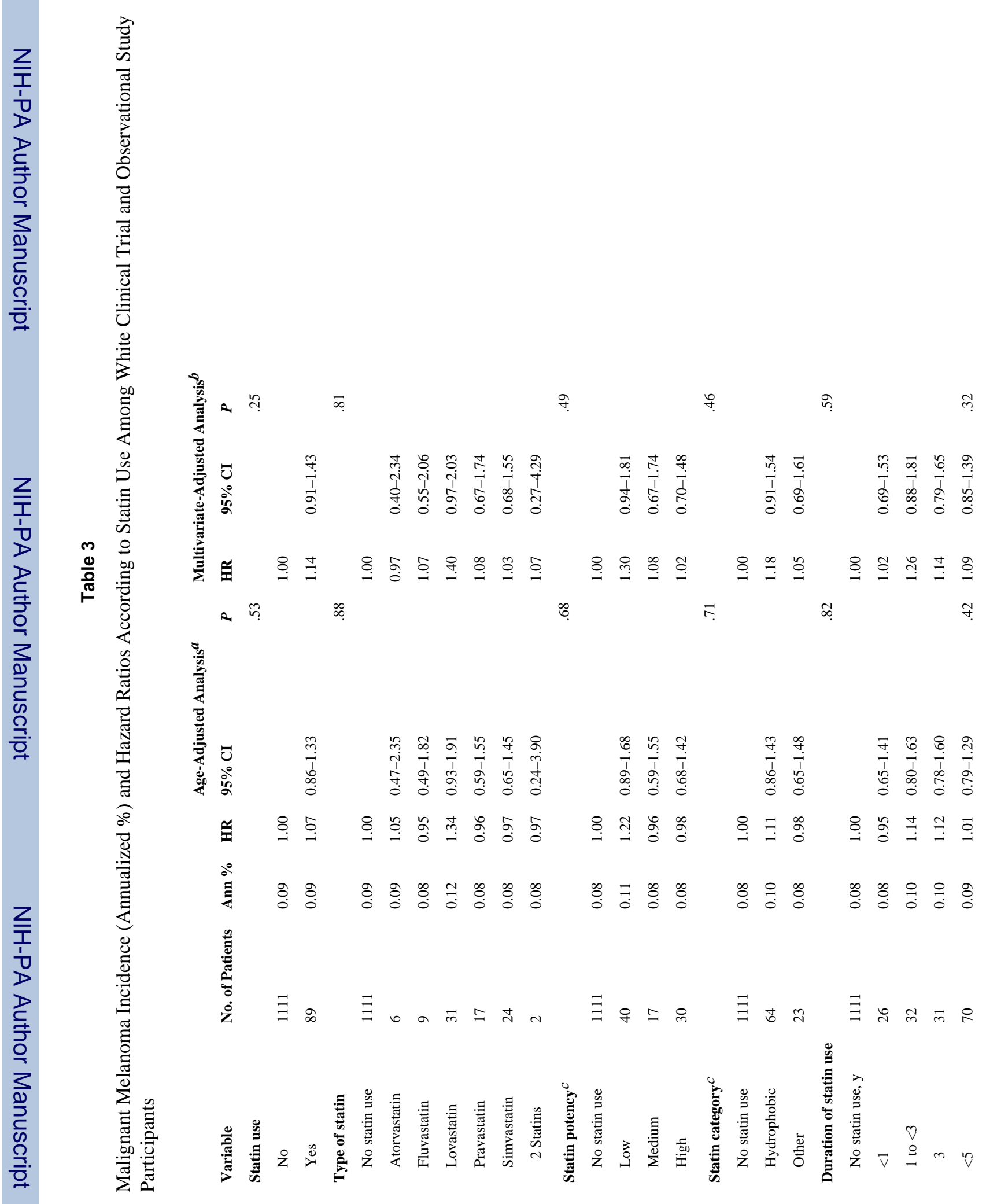




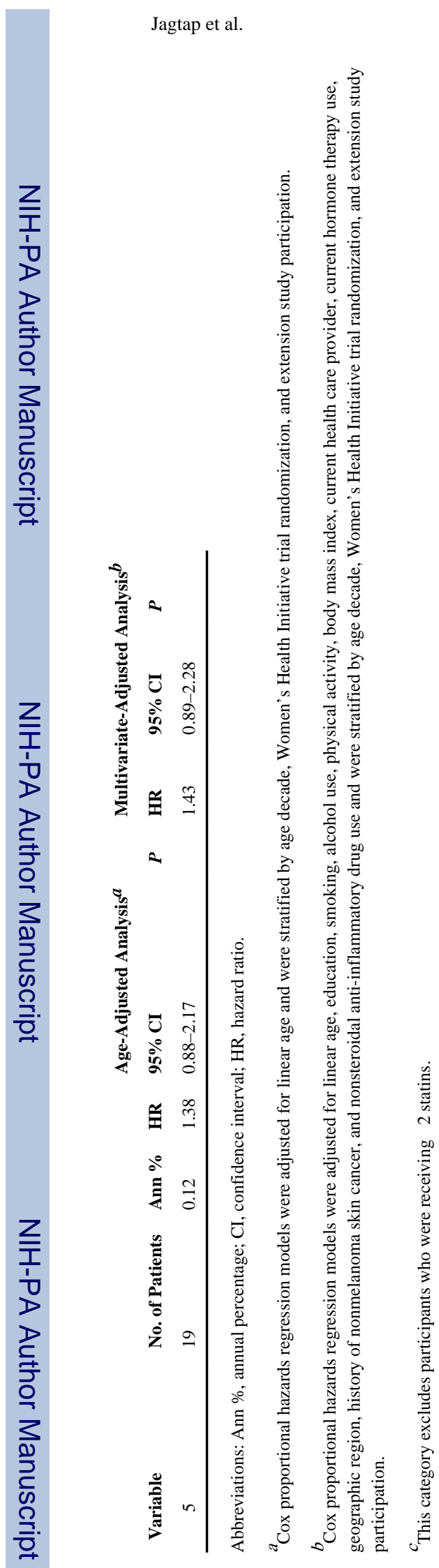

Cancer. Author manuscript; available in PMC 2013 October 19. 


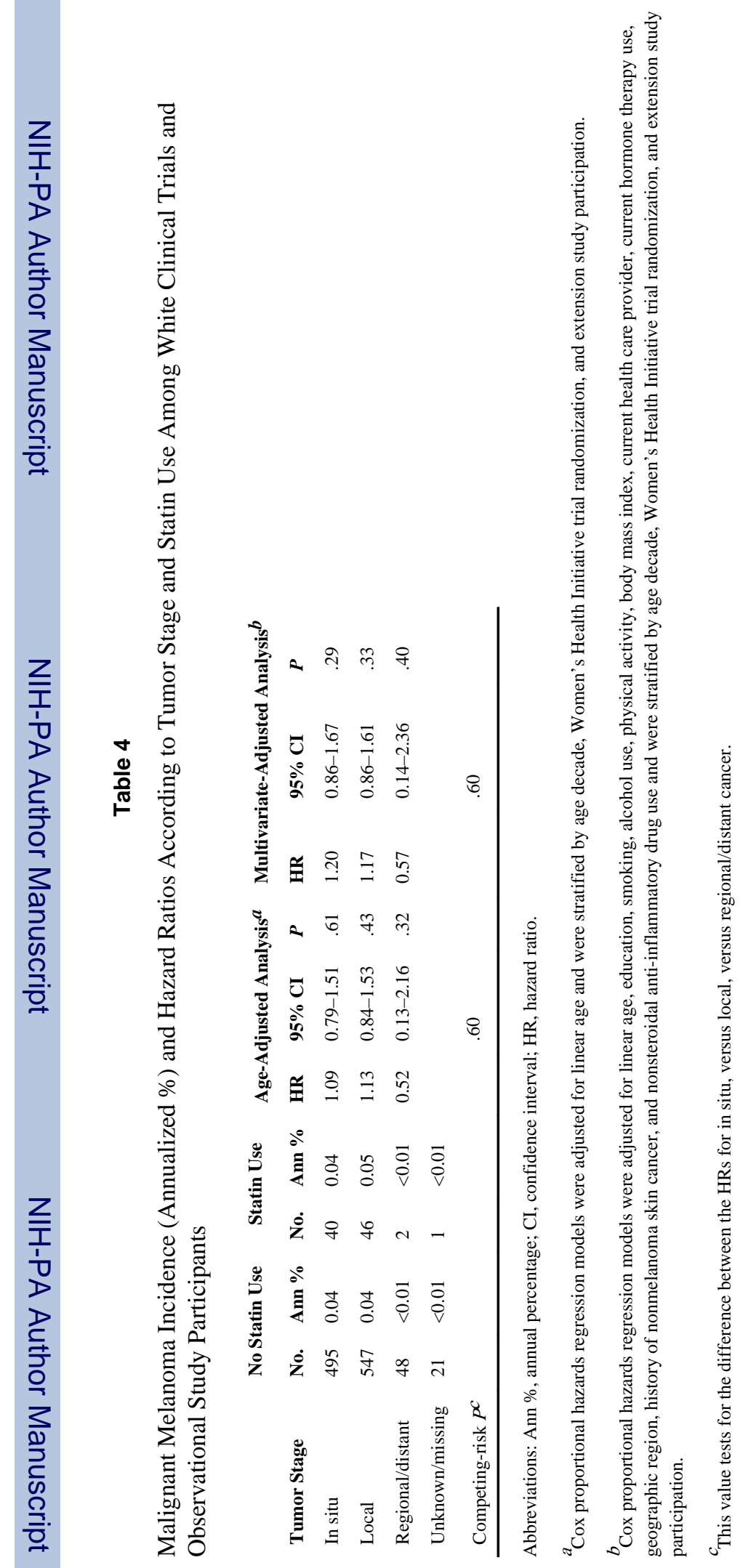

